\title{
JOMSTI
}

\section{Analisis Lagu Toraja Marendeng Marampa Aransemen Tindoki Band}

\author{
Linesti Lamba ${ }^{1}$, Ni Wayan Ardini ${ }^{2}$, I Komang Darmayuda ${ }^{3}$, Ketut Sumerjana ${ }^{4}$ \\ ${ }^{1}$ Musisi, ${ }^{234}$ Program Studi Musik, Fakultas Seni Pertunjukan \\ Institut Seni Indonesia Denpasar \\ email: 1 linestilamba11@gmail.com, ${ }^{2}$ niwayanardini17@gmail.com, \\ ${ }^{3}$ komangdarmayuda2804@gmail.com, ${ }^{4}$ ketutsumerjana@isi-dps.ac.id.
}

\begin{abstract}
This study aims to describe the musical form of Marendeng Marampa'", a local song in Toraja, Tana Toraja Regency, South Sulawesi Province, Indonesia, arranged by the Tindoki Band. The qualitative data in this research are obtained by doing observation, interviews, documentation, and discography. The results of this research show that " Marendeng Marampa"' arranged by Tindoki Band have two parts, i.e. the form $A-B$, with the sequence $A-A^{\prime} A-A-A^{\prime}-B-B-B$ " consisting of several figures, motives, phrases (antecedent phrase and consequent phrase). Its musical instruments used in this arrangement are collaboration between the traditional musical instruments in Toraja, including Toraja gandang, Toraja flute, basin bassin/tulali, karombi, and modern (Western) music, i.e. electric guitar, bass guitar, keyboard, and electric drums, which lyrics are incorporated into the arrangement of Ma'bugi and Manimbong. Marendeng Marampa'" means safe, peaceful land of birth and is also a unifying song for the people of Toraja. The song is a reminiscent for the people of Toraja to remind their home region that tondok kadadian is their land of birth.
\end{abstract}

Keywords: musical form, Toraja song, " Marendeng Marampa'".

\begin{abstract}
ABSTRAK
Penelitian ini bertujuan mendeskripsikan bentuk musikal Marendeng Marampa", sebuah lagu rakyat di Toraja di Kabupaten Tana Toraja, Provinsi Sulawesi Selatan, Indonesia, yang diaransemen oleh Tindoki Band. Data dalam penelitian kualitatif ini diperoleh dengan observasi, wawancara, dokumentasi, dan diskografi. Hasil penelitian menunjukkan bahwa Marendeng Marampa'" aransemen Tindoki Band mempunyai bentuk dua bagian, yaitu bentuk $A-B$, dengan urutan $A-A$ '-A-A'-B-B'-B" yang terdiri atas beberapa figur, motif, frase baik itu frase anteseden dan frase konsekuen. Alat musik yang digunakan dalam aransemen ini adalah kolaborasi alat musik tradisional asal Toraja, seperti musik gandang Toraja, suling Toraja, basinbassin/tulali, karombi, dan alat musik modern (Barat), yaitu gitar elektrik, gitar bass, keyboard, drum elektrik, serta syair yang digabungkan ke dalam aransemen Ma'bugi dan Manimbong. Marendeng Marampa'" yang dimaksud adalah aman tentram tanah kelahiran. Lagu pemersatu bagi orang Toraja mengingatkan tondok kadadian yang berarti tanah kelahiran.
\end{abstract}

Kata kunci: bentuk musik, lagu Toraja, Marendeng Marampa'”. 


\section{PENDAHULUAN}

Musik merupakan salah satu media ungkapan kesenian melalui sebuah bunyi yang unsur dasarnya berupa melodi, irama, dan harmoni, dengan unsur pendukung berupa bentuk gagasan, sifat, dan warna bunyi (Syafiq, 2003: 203). Musik juga merupakan suatu hasil karya seni berupa bunyi dalam bentuk lagu yang mengungkapkan pikiran dan perasaan penciptanya melalui unsur-unsur pokok musik, yaitu irama, melodi, harmoni, dan bentuk atau struktur lagu serta ekspresi sebagai suatu kesatuan (Jamalus, 1988: 1).

Umumnya karya musik dapat dibagi menjadi tiga jenis, yaitu musik vokal, musik instrumental, dan gabungan antarkeduanya. Musik vokal merupakan musik yang dihasilkan dari suara manusia sedangkan musik instrumental merupakan musik tanpa syair dalam bentuk instrumen apa pun. Terakhir musik gabungan adalah gabungan antara musik vokal dan musik instrumental. Di dalam musik yang teratur terdapat unsur-unsur musik, yaitu melodi, irama, birama, harmoni, tangga nada, tempo, dinamika, timbre. Untuk mengetahui unsur-unsur tersebut perlu adanya analisis bentuk lagu. Dalam hal ini penulis (Linesti Lamba) tertarik menganalisis bentuk sebuah lagu daerah tempat penulis berasal, yaitu lagu Toraja.

Setiap daerah di Indonesia memiliki lagu-lagu daerah yang menjadi ciri khasnya. Ciri khas lagu-lagu tersebut setidaknya terdapat dalam bahasa yang digunakan dalam lirik/syair lagu, seperti Marendeng Marampa" dari Toraja yang dibahas dalam kesempatan ini. Toraja sendiri terletak di Kabupaten Tana Toraja, Provinsi Sulawesi Selatan. Kabupaten Tana Toraja saat ini merupakan salah satu tujuan wisata baik untuk wisatawan lokal maupun wisatawan mancanegara. Toraja sangat terkenal dengan budaya rambu tuka' dan rambu solo', di mana rambu tuka' identik dengan pesta syukuran dan pernikahan sedangkan rambu solo' identik dengan acara kematian.

Saat ini banyak musik berkembang dalam bentuk baru, baik itu hasil pengolahan dari musik tradisi (etnik) ataupun perkembangan lebih lanjut musik modern. Musik etnik modern adalah sebuah penggabungkan musik tradisional dengan musik modern. Di Indonesia cukup banyak grup musik yang bereksperimen untuk mengabungkan alat musik etnik dengan alat musik Barat.

Sejumlah seniman di Tana Toraja berupaya menggabungkan musik etnik Toraja dengan mengkolaborasikan dengan musik modern. Beberapa nama yang 
dapat disebut dalam jalur ini adalah Harry Mantong, Tonkin Bay, hingga Tindoki Band. Tindoki Band membawakan lagu-lagu Toraja yang diaransemen dengan mengkolaborasikan musik tradisional Toraja dengan musik modern dengan tujuan agar lebih diterima oleh masyarakat.

Salah satu lagu yang diaransemen Tindoki Band adalah Marendeng Marampa'" yang merupakan lagu pop daerah Toraja di mana lagu ini sebagai lagu rakyat (folk song) tidak diketahui nama penciptanya (no name atau anonim). Marendeng Marampa"' merupakan lagu pemersatu anak daerah Toraja terutama bagi mereka yang merantau ke daerah lain agar selalu mengingat dan mengenang kampung halaman. Liriknya mengungkapkan bahwa Toraja yang damai, tentram, tempat kelahiran dan menggambarkan alam Toraja yang indah, sebagai tanah kelahiran, dan juga falsafah hidup orang Toraja yang bekerja keras di tanah orang untuk hidup walaupun pedih dan susah (maparri' masussa). Orang Toraja sepenuhnya sadar bahwa itu adalah konsekuensi hidup yang harus diterima (iamo passanan tengko ki, umpasundun rongko' ki).

Aransemen Marendeng Marampa"' karya Tindoki Band sangat menarik, dan unik. Bahasa Toraja identik dengan simbol tanda koma di atas (') di akhir kata misalnya "Marampa". Simbol tersebut mengingatkan kembali kepada orang Toraja yang merantau untuk selalu mengingat Toraja meskipun susah atau senang yang dialami, namun Toraja tempat kelahiran memberi semangat atau spirit. Dalam aransemen ini Tindoki Band menampilkan alat musik Toraja yang hampir punah seperti karombi, bassin-bassin dan alat musik dari bambu. Vokalis Tindoki Band, Laso' Rinding Sombolinggi' (alias Mongnge) menjelaskan kekhawatirannya akan generasi muda Toraja yang sekarang mulai melupakan adat dan budaya Toraja, khususnya bahasa Toraja. Kenyataannya, banyak generasi muda setempat yang merasa gengsi dengan bahasa Toraja termasuk lagu-lagu Toraja, sehingga sesuai dengan nama Tindoki yang memiliki arti: mimpi kami untuk membangun kembali kepekaan anak muda Toraja untuk terus melestarikan budayanya yang kaya itu.

Lagu-lagu aransemen Tindoki Band tidak hanya dipentaskan di Toraja. Marendeng Marampa"' pernah bergema di Italia yang dinyanyikan oleh Toraja Choir dari Italia di samping pernah dinyanyikan oleh Lea Simanjuntak yang di-medley-kan dengan lagu "O Ina Ni Keke", "Angin Mamiri" dan "Sipatokan" dalam acara "Konser Real Wow" dengan tema "Sound from the East" yang diiringi oleh Barry Likumahuwa 
\& Friends. Dalam kegiatan Aliansi Masyarakat Adat Nusantara yang terkait dengan peringatan Hari Internasional Masyarakat Adat Sedunia, Grup Tindoki Band diundang untuk berpartisipasi pada tanggal 09-10 Agustus 2015 di Toya Bungkah, Batur, Kintamani, Bali, dengan membawakan Marendeng Marampa"', "Batingna Lebonna", dan "Lembang Sura".

Tindoki Band kerap menggabungkan unsur musik modern dan musik asli Toraja. Lagu-lagu lama Toraja digali dan dikembangkan dengan konteks kekinian tanpa mengubah esensi dan pesan yang hendak disampaikan dalam lagu tersebut. Salah satu lagu Toraja yang diangkat kembali adalah Marendeng Marampa"' di mana Tindoki Band mengunakan instrumen musik etnik Toraja dan jenis musik lainnya. Lagu ini diaransemen oleh Tindoki Band dengan mengkolaborasikan musik tradisional Toraja yang saat ini hampir punah dengan musik modern, sehingga penulis ingin mengetahui unsur-unsur apa saja yang terdapat dalam komposisi Marendeng Marampa'" aransemen Tindoki Band.

\section{METODE PENELITIAN}

Penelitian ini menggunakan metode kualitatif. Menurut Moleong (2007: 6), penelitian kualitatif adalah penelitian yang bermaksud untuk memahami fenomena tentang apa yang dialami oleh subjek penelitian misalnya perilaku, persepsi, motivasi, dan tindakan. Secara holistik dan dengan cara deskripsi dalam bentuk kata-kata dan bahasa pada konteks khusus yang alamiah dan dengan memanfaatkan berbagai metode alamiah. Di dalam teknik pengumpulan datanya, penulis menggunakan observasi, wawancara, dokumentasi, dan diskografi.

Eksplanasi dalam tulisan ini berada dijalur yang sama dengan penelitian teks musik yang membicarakan musik etnis dan musik barat sebagaimana artikel Mahardika (2018,https://jurnal.isi-dps.ac.id/index.php/jomsti/article/view/505) dan Matanari (2019, https://jurnal.isi-dps.ac.id/index.php/jomsti/article/view/612) Analisis dalam tulisan ini dalam beberapa hal, serupa dengan yang diupayakan oleh Ariesta (2017 dan 2018, https://jurnal.isi-dps.ac.id/index.php/jomsti/article/view/504) dan Putra (2019, https://jurnal.isi-dps.ac.id/index.php/jomsti/article/view/604). 


\section{PEMBAHASAN}

Grup musik Tindoki Band terbentuk pada tanggal 14 April 2014 dengan tujuh personal, yakni Laso' Rinding Allo sebagai vokalis, Hardi Rupang sebagai pemain keyboard, Aland Rison sebagai pemain gitar, Dion Virgiawan sebagai pemain bass, Fahyul Roberto sebagai pemain drum, Asdem Lebang sebagai pemain perkusi, Silvanus Bandangan sebagai pemain suling. Profesi mereka beragam. Selain memiliki kemampuan bermusik, mereka juga mempunyai kemampuan seni lainnya.

Tindoki Band mengaransemen dengan menggabungkan unsur musik modern dan musik tradisional Toraja. Lagu-lagu lama Toraja digali dalam konteks kekinian tanpa mengubah esensi dan pesan yang hendak disampaikannya. Salah satu lagu Toraja yang diangkat kembali adalah Marendeng Marampa'”. Saat ini Tindoki Band sedang merampungkan album perdana, dan riset tentang alat musik tradisional Toraja yang hampir punah.

Dalam aransemen Marendeng Marampa", Tindoki Band masih mempertahankan lagu aslinya tanpa mengubah liriknya. Aransemen ini memiliki durasi 6 menit 40 detik dengan proses intro dimulai dari gitar kemudian selang beberapa menit masuk drum dan basin-bassin/tulali, dan dilanjutkan dengan vokal sebagai melodi pokok. Instrumen yang digunakan dalam aransemen ini yaitu vokal, gitar, drum, suling, keyboard, bass, tari dan nyanyian (ondo pua), manimbong.

Lirik lagu Marendeng Marampa'” adalah sebagai berikut.

\begin{tabular}{l|l} 
Marendeng Marampa'” kadadianku & Aman tentram selalu tempat kelahiranku \\
Dio padang digente' Toraya & Di Tana Toraja \\
Lebukan Sulawesi & Wilayah berlembah gunung-gunung dan \\
Mellombok membuntu mentanetena & bukit-bukit \\
Nakabu' uma sia pa'lak & Hamparan sawah dan ladang yang dialiri \\
Nasakkai' salu Sa'dan & sungai Sa'dan \\
Kami sang Torayan & Kami orang Toraja \\
Umba-umba padang kiolai & Ke negeri mana pun kami pergi (tempati) \\
Maparri' masussa kirampoi & Kesulitan kesusahan yang kami temui tidak \\
Tangki pomabanda' penawa & akan membuat kami putus asa \\
Yamo passanan tengkoki & Karena sudah tanggung jawab kami \\
Umpasundun rongko'ki & Menyempurnakan kejayaan kami). \\
\hline
\end{tabular}

Marendeng Marampa" berarti aman tentram tanah kelahiran. Lagu ini mengingatkan bagi orang-orang Toraja yang merantau bahwa apa pun yang dialami di rantau orang karena Marendeng Marampa"' mengingatkan kembali akan tondok 
kadadian yang berarti tanah kelahiran. Marendeng Marampa'" dari lirik yang terdapat pada baris 1 dan 2 tersebut adalah di mana keadaan yang selalu aman dan tentram tempat lahir saya (kadadianku) yang dimaksudkan adalah Tana Toraja sendiri. Toleransi antar-agama di Toraja sangat dipegang erat. Meskipun di Toraja mayoritas penduduk beragama Kristen namun perbedaan agama bukanlah penghalang untuk menjadi satu seperti dalam Marendeng Marampa"'.

Marendeng Marampa'" dari baris ketiga dan keempat adalah keadaan alam di Toraja yang berlembah (mellombok) dan banyak gunung meskipun itu tidak aktif (membuntu) dan bukit-bukit (mentanetena) yang menunjukkan Toraja memiliki keadaan alam yang dingin. Hamparan sawah (uma) dan ladang (pa'lak) menunjukkan sebagian dari orang Toraja mata pencahariannya adalah petani.

Marendeng Marampa'" pada bait kedua pada baris 1 dan 2 adalah ke negeri mana pun orang Toraja pergi/tempati tidak menyurutkan semangat untuk tetap bekerja dengan baik. Dilanjutkan pada baris ketiga dan keempat sebagai berikut: Marendeng Marampa'"-nya adalah tidak akan mudah putus asa (menyerah) dan apa pun kesulitan (maparri') dan kesusahan (masussa) yang dihadapi tidak luput karena semuanya itu harus diserahkan kepada Tuhan dan tak kalah penting yaitu disertai dengan usaha.

Baris kelima dan keenam adalah sebagai berikut: Marendeng Marampa"'nya adalah sudah menjadi tanggung jawab kami. Maksudnya adalah salah satu tujuan orang Toraja merantau untuk memenuhi tanggung jawab dari keluarga dan setelah kembali mereka sudah berhasil dan membuat keluarga bangga.

Marendeng Marampa'" tergolong dalam bentuk lagu dua bagian, yaitu A-A'-AA'-B-B'-B" di mana lagu ini diawali dengan Intro. Introduksi adalah bagian yang muncul pada awal sebuah komposisi dan berfungsi sebagai prolog atau prawacana (kata pengantar) untuk memasuki bagian yang utama komposisi tersebut (Miller, 170). Introduksi ini dimulai dari birama 1 sampai birama 18 yang merupakan frase pembuka dari aransemen Marendeng Marampa'". Pada bagian introduksi lagu, birama 1-2 dengan dua birama sebagai awal dimulainya sebuah lagu menggambarkan suara angin sebelum masuk bagian gitardi mana pada birama ini tidak dinotasikan. Masih pada bagian introduksi birama 3-18 dengan jumlah 16 birama, gitar menjadi pengiring vokal di mana gitar memakai pola permainan 
interlooking (kait-mengait). Hal ini terlihat dengan adanya repetisi motif pada birama 3-18.

Bagian A merupakan periode yang terdiri atas dua frase, yaitu frase anteseden (tanya) dan frase konsekuen (jawab). Menurut Prier (1996: 2), periode adalah sejumlah ruang birama (biasanya 8 atau 16 birama) yang merupakan suatu kesatuan (Ariesta, 2017; Ariesta, et al, 2018). Untuk kalimat periode umumnya dipakai huruf besar ( $A, B, C$, dsb). Bila sebuah kalimat/periode diulang dengan disertai perubahan, huruf-huruf besar disertai tanda aksen ('), misalnya A,B,A'. Bagian ini memakai sukat $4 / 4$ yang berarti bahwa dalam satu birama terdiri atas empat ketukan.

Tempo yang dipakai dalam bagian ini $\cdot=125 \mathrm{MM}$ merupakan tempo cepat dan gembira, dan terdapat tanda mula satu kress yang berarti bahwa aransemen ini dimainkan dengan nada dasar $\mathrm{G}=$ do. Tanda dinamika yang digunakan pada bagian ini adalah forte ( $f$. Dinamika adalah keras lembutnya dalam bermain musik, dinyatakan dengan berbagai macam istilah, seperti forte $(f)$ yang merupakan dinamika keras (Banoe, dalam Ariesta, 2017; Ariesta, et al, 2018). Pada bagian A, dinamika, frase anteseden (tanya) dan frase konsekuen (jawab) dapat dilihat pada Gambar 1.
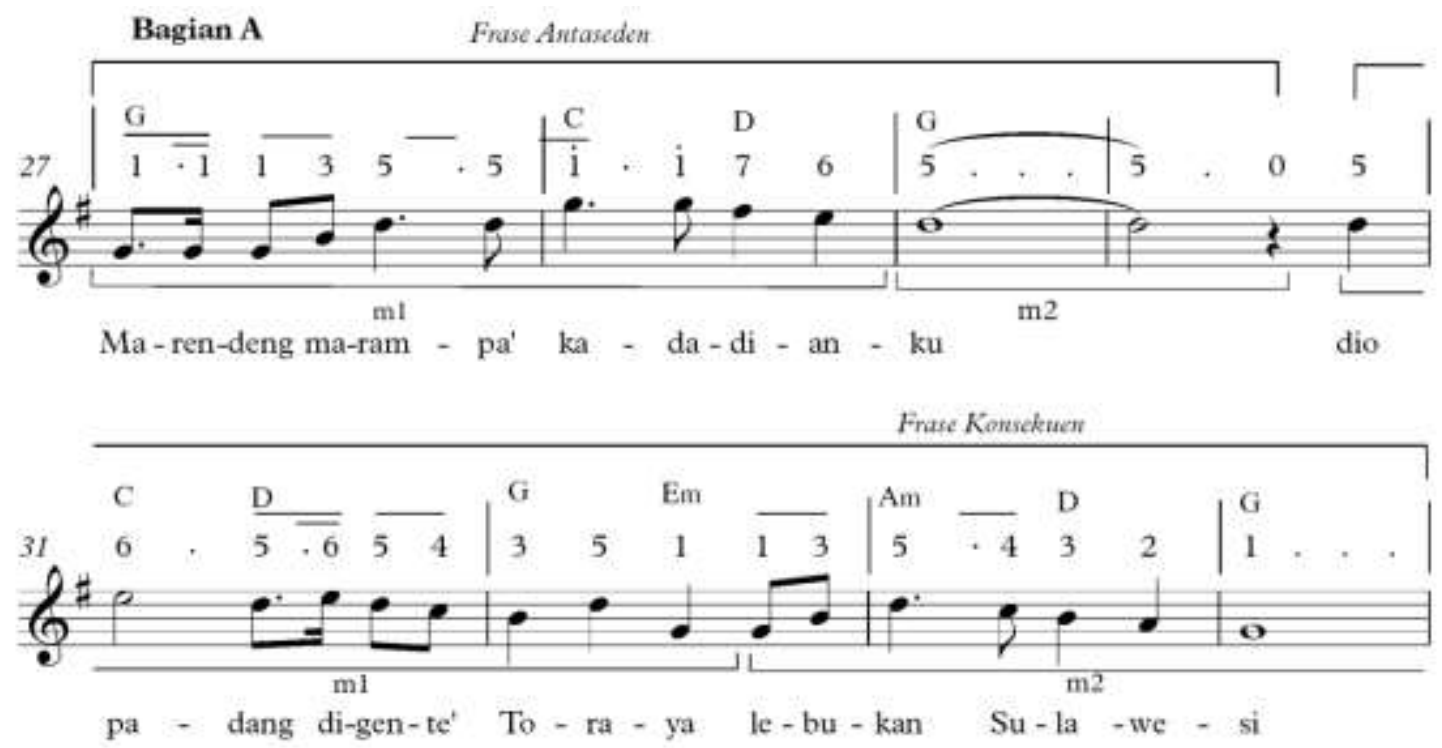

Notasi 1. 
Bagian ini terdiri atas 8 birama yang dimulai dari birama 27 pada awal ketukan sampai dengan birama 39. Bagian ini terdiri atas dua frase, yaitu frase anteseden dan frase konsekuen yang masing-masing frase terdapat satu semi frase. Masing-masing frase dan semi frase pada bagian ini dapat dimulai dari frase anteseden.

Frase anteseden pada bagian ini dimulai pada birama 27 ketukan awal sampai birama 30 di ketukan awal. Bagian ini merupakan semi kadens. Menurut Prier (1996: 2), frase anteseden adalah awal kalimat atau sejumlah birama (biasanya birama 1-4 atau 1-8) biasa disebut frase tanya atau frase depan karena biasanya ia berhenti dengan nada yang mengambang/menggantung yang umumnya di sini terdapat akord dominan (Ariesta, 2017; Ariesta, et al, 2018). Kesannya adalah lagu belum selesai atau masih dinantikan jawaban dari lagu tersebut (Gambar 2).

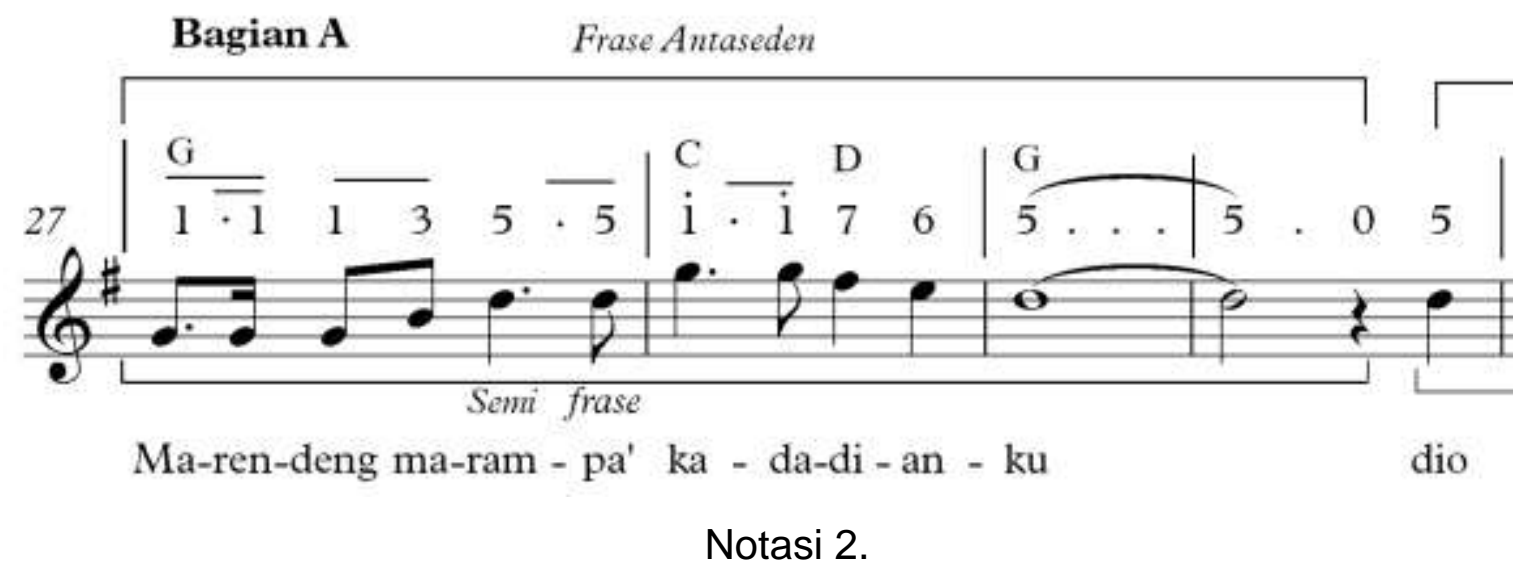

Frase ini terdiri atas empat birama, dan terdapat satu semi frase. Semi frase pada Gambar 2 menegaskan adanya setengah kalimat yang bagus dalam pengolahan vokal, khususnya untuk yang menyanyikan lagu ini. Kemudian dari frase anteseden dan semi frase ini terdiri atas dua buah motif, yang diberi masing-masing simbol m1, m2. Menurut Prier (2011: 26), motif adalah bagian terkecil dalam sebuah lagu di mana motif merupakan sepotong lagu atau sekelompok nada yang kesatuan dengan memuat arti dalam dirinya sendiri. Motif juga bisa diolah dan dimainkan berulang-ulang. Dalam frase anteseden ini terdapat dua motif di mana motif yang satu memancing datangnya motif yang lain, yang dengan demikian musik tampak sebagai suatu proses, sebagai suatu pertumbuhan. 
Frase konsekuen pada bagian ini dimulai dari birama 30 ketukan akhir dan berakhir pada birama 34 ketukan awal. Menurut Prier (1996: 2), frase konsekuen adalah bagian kedua dari kalimat (biasanya birama 5-8 atau 9-16) biasa disebut frase jawaban atau frase belakang dalam suatu kalimat dalam lagu dan pada umumnya jatuh pada akord tonika dalam (Ariesta, 2017; Ariesta, et al, 2018). Pada frase konsekuen terdapat empat birama dan terdapat satu semi frase, untuk mengetahui tentang semi frase pada bagian konsekuen tersebut (Gambar 3).

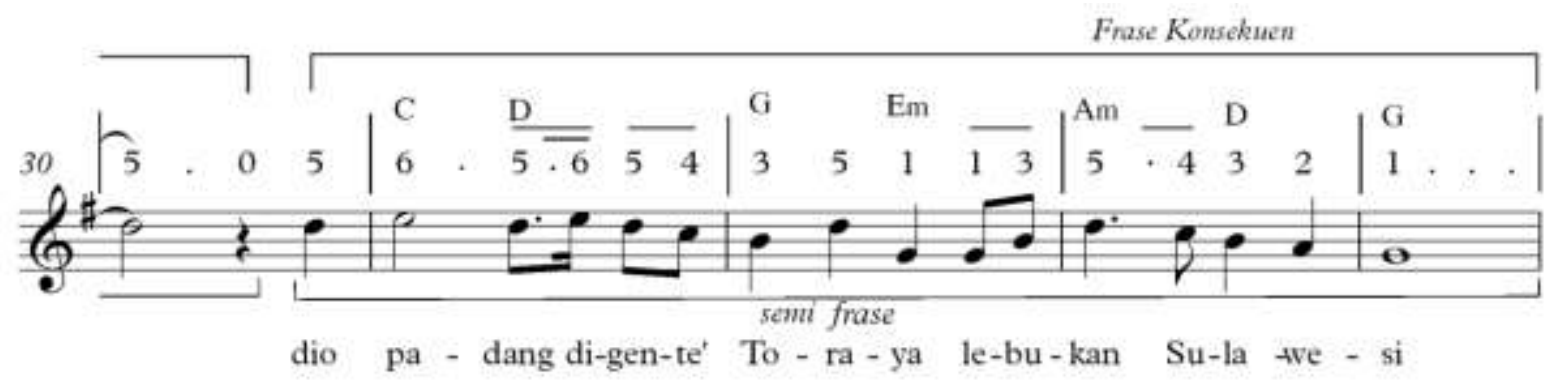

Notasi 3.

Pada frase konsekuen terdapat satu semi frase pada bagian konsekuen dan pada frase konsekuen ini terdapat dua potongan motif yang diberi simbol m1, m2. Motif 1 dan motif 2 merupakan satu kesatuan di mana motif yang satu memancing datangnya motif yang lain, yang dengan demikian musik tampak sebagai suatu proses, sebagai suatu pertumbuhan, sehingga menjadi sebuah jawaban dari motif sebelumnya.

Pada bagian A terdapat beberapa pengulangan harfiah sebelum masuk lagu bagian B. Prier (1996: 27) mengatakan bahwa motif ulangan harfiah adalah mengintensifkan suatu kesan (misalnya keheningan malam) atau ulangannya untuk menegaskan suatu pesan (Gambar 4). 

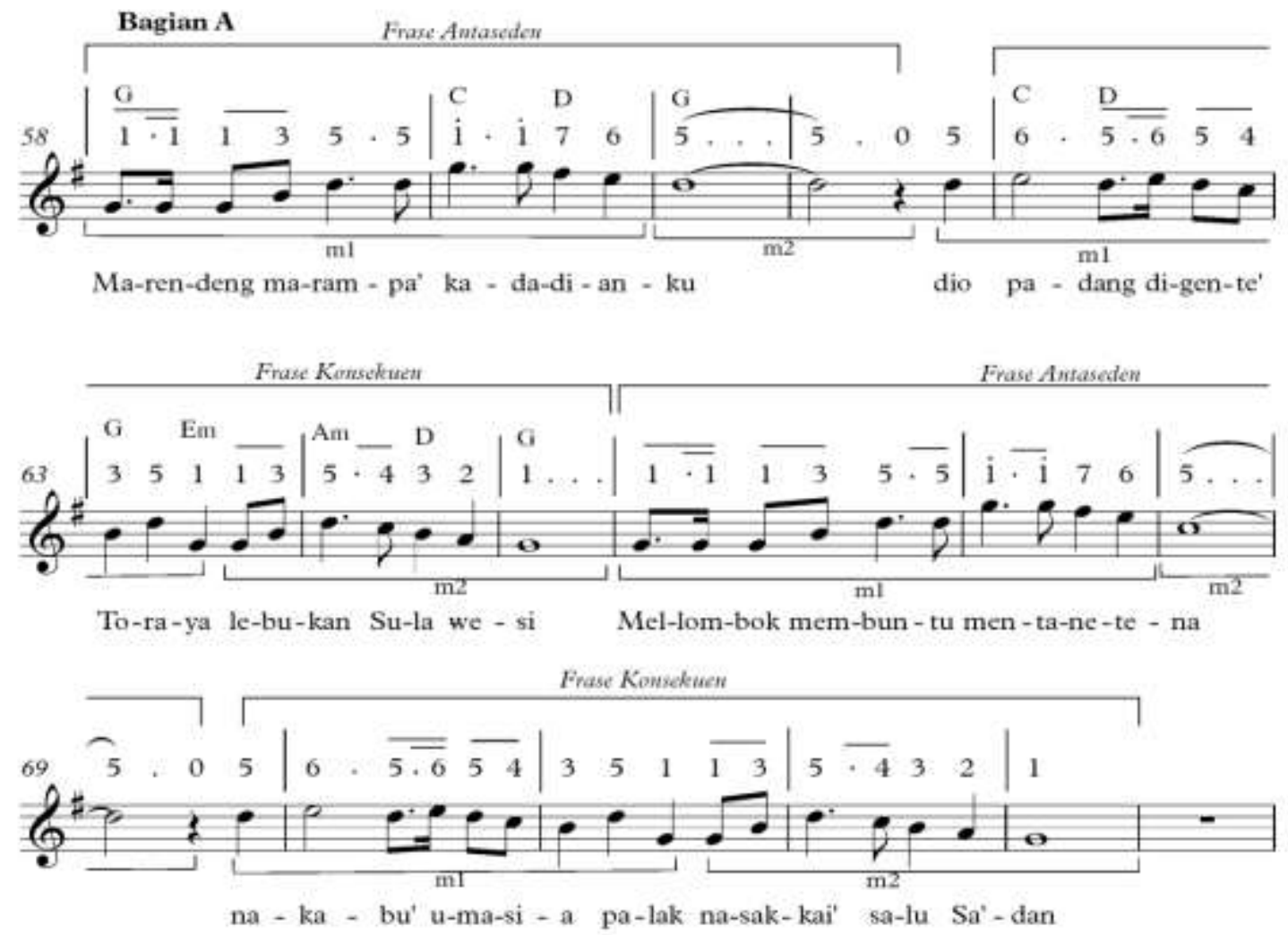

Notasi 4.

Bagian B merupakan periode yang memiliki dua frase, yaitu frase anteseden dan frase konsekuen. Bagian B juga terdiri atas motif, semi frase. Bagian ini terdiri atas enam chord di mana dalam satu birama terdapat satu dan dua chord dengan hitungan empat ketuk yang dimulai dari akord satu. Tempo yang digunakan pada bagian ini adalah MM yang merupakan tempo cepat dan gembira. Pada bagian ini terdapat tanda mula satu kress yang berarti bahwa bagian ini memiliki nada dasar $\mathrm{G}=$ do. Tanda dinamika yang digunakan adalah mezzo forte (mf) yang artinya cukup keras, terlihat pada kata "Kami sang Torayan" yang menegaskan: kami adalah orang Toraja. Dinamika, frase anteseden (tanya) dan frase konsekuen (jawab) dapat dilihat pada Gambar 5. 


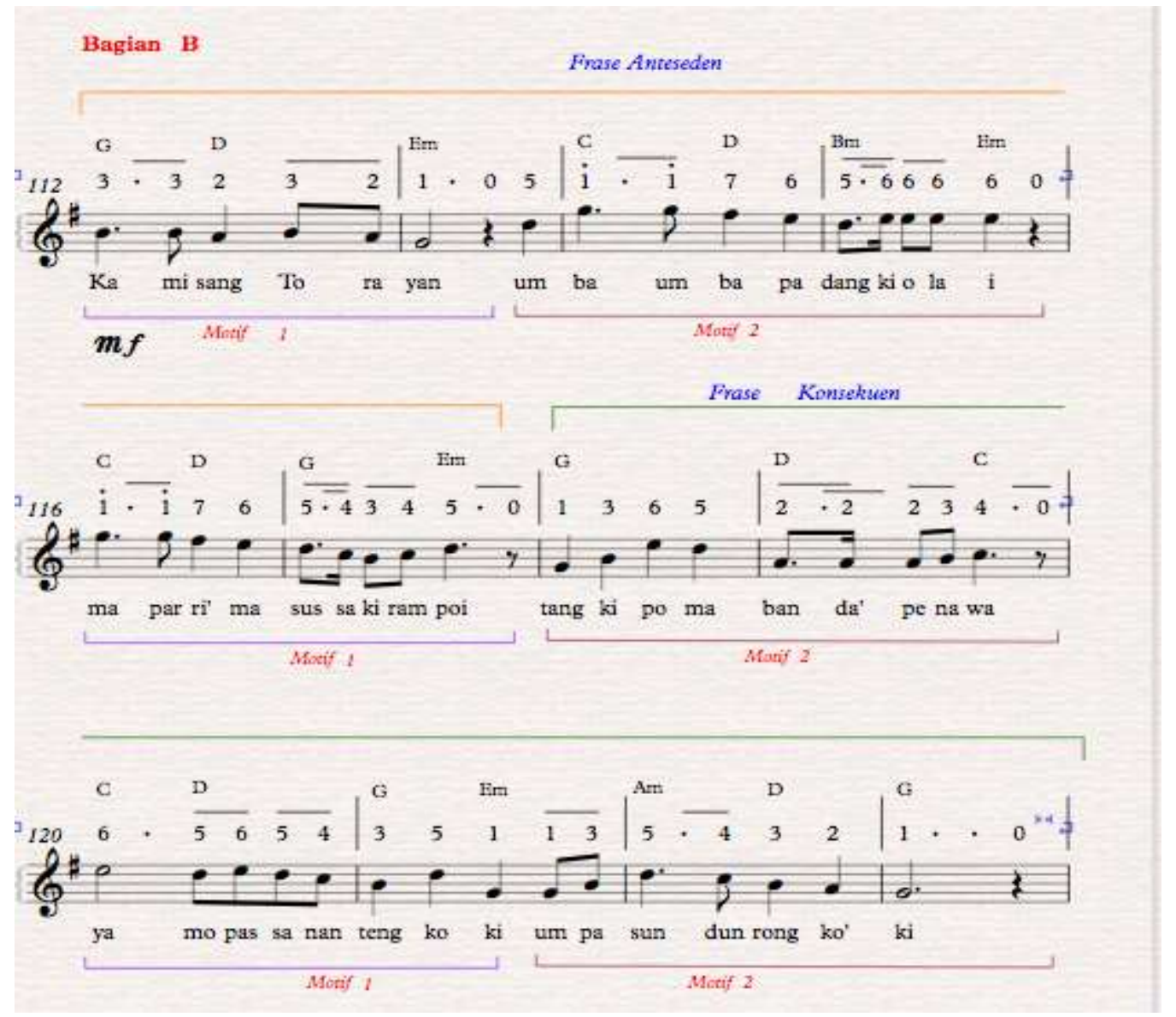

Notasi 5.

Pada Gambar 5, bagian ini terdiri atas 12 birama yang dimulai dari birama 112 pada awal ketukan sampai dengan birama 123. Bagian ini terdiri atas dua frase, yaitu frase anteseden dan frase konsekuen yang masing-masing frase terdapat satu semi frase. Masing-masing frase dan semi frase pada bagian ini, dapat dimulai dari frase anteseden.

Frase anteseden pada bagian ini dimulai pada birama 112 ketukan awal sampai birama 123 di ketukan awal. Bagian ini merupakan semi kadens. Menurut Prier (1996: 2), frase anteseden adalah awal kalimat atau sejumlah birama (biasanya birama 1-4 atau 1-8) biasa disebut frase tanya atau frase depan karena biasanya ia berhenti dengan nada yang mengambang/menggantung. Umumnya di sini terdapat akord dominan (Ariesta, 2017; Ariesta, et al, 2018). Kesannya adalah lagu belum selesai atau masih dinantikan jawaban dari lagu tersebut.

Frase ini terdiri atas enam birama dan terdapat satu semi frase. Semi frase pada Gambar 5 menegaskan adanya setengah kalimat yang bagus dalam pengolahan vokal, khususnya untuk yang menyanyikan lagu ini. Kemudian frase 
anteseden dan semi frase ini terdiri atas dua buah motif di mana motif diberi masingmasing simbol m1, m2 (Gambar 6).
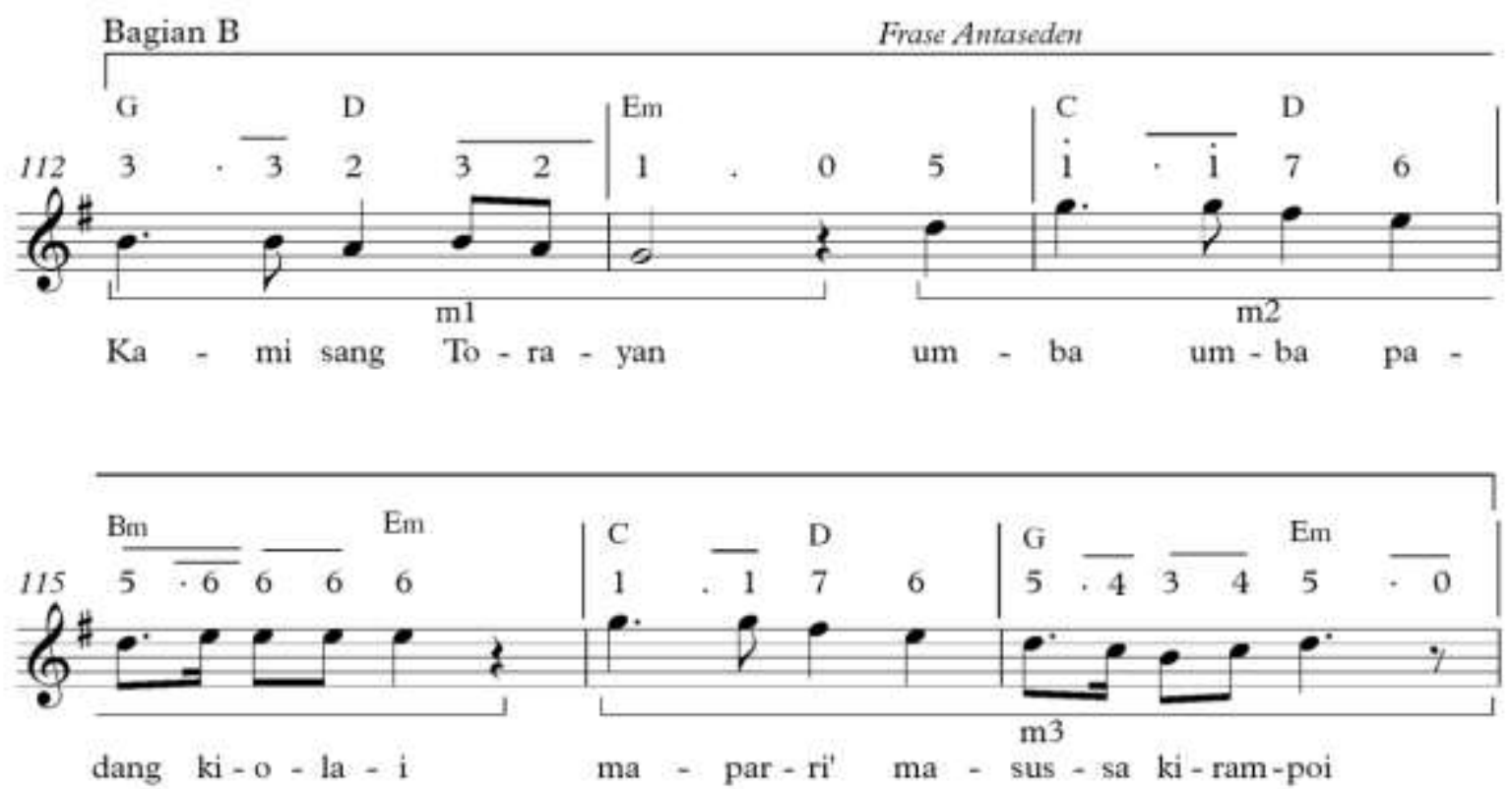

Notasi 6.

Gambar 6 menunjukkan bahwa ada tiga potongan motif pada frase anteseden dari birama 124 sampai dengan birama 129 di mana motif yang satu memancing datangnya motif yang lain.

Frase konsekuen pada bagian ini dimulai dari birama 130 ketukan awal dan berakhir pada birama 135 ketukan awal. Menurut Prier (1996: 2), frase konsekuen adalah bagian kedua dari kalimat (biasanya birama 5-8 atau 9-16) atau biasa disebut frase jawaban atau frase belakang dalam suatu kalimat dalam lagu dan pada umumnya jatuh pada akord tonika (Ariesta, 2017; Ariesta, et al, 2018). Frase konsekuen memiliki semi frase dan motif (Gambar 7). 

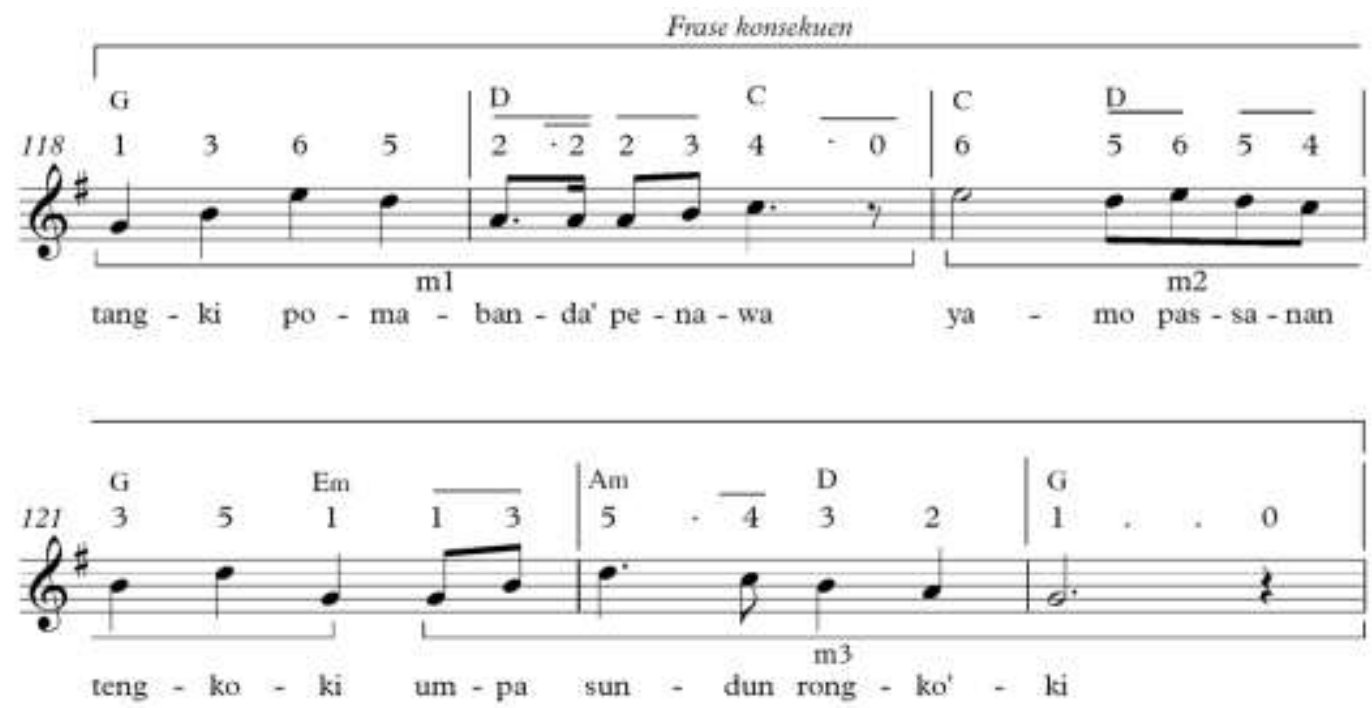

Notasi 7.

Dalam Gambar 7, frase konsekuen memiliki motif sebanyak tiga potongan. Terdapat beberapa improvisasi seperti instrumen gandang Toraja dan syair/nyanyian yang sering disebut meoli yang artinya berteriak yang juga dimasukkan ke dalam aransemen ini pada birama 102 yang disertai dengan improvisasi dari suling yang terus bermain. Sementara itu di sela-sela permainan improvisasi dari suling, ada juga suara meoli yang liriknya hanya satu kata, yaitu Toraya.

Pengulangan bagian B secara harfiah juga terjadi di bagian ini (Notasi 8). Gambar 8 menunjukkan bahwa ada pengulangan secara harfiah pada bagian B. Ending lagu ini adalah improvisasi dengan Manimbong yang merupakan semacam lantunan syair yang dipanjatkan di mana lantunan syair ini adalah sebuah ungkapan rasa syukur kepada Tuhan. 


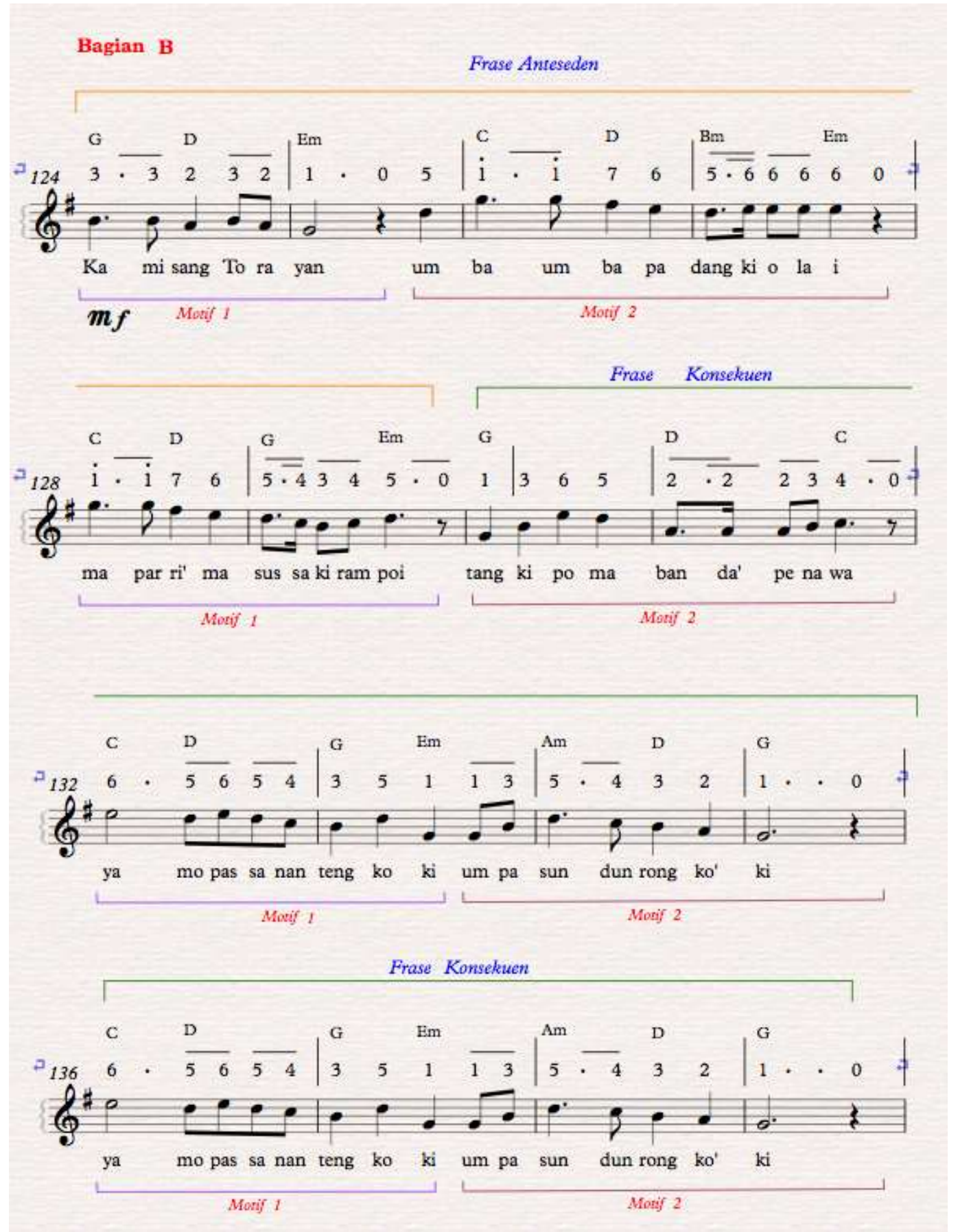

Notasi 8.

\section{SIMPULAN}

Marendeng Marampa"' adalah lagu anonim yang berasal dari Toraja yang merupakan lagu pop daerah setempat. Alat musik yang digunakan dalam aransemen Tindoki Band berdurasi 6 menit 40 detik ini terdiri atas delapan instrumen dengan dua lantunan syair yang berbeda. Vokal merupakan melodi pokok 
kemudian terdapat gandang Toraja, gitar elektrik, gitar bass, keyboard, suling Toraja, basin-bassin/tulali, karombi.

Aransemen Marendeng Marampa"' bernada dasar $\mathrm{G}=$ do dan tempo 125 MM dengan tanda perubahan yang berarti cepat dan gembira serta memakai sukat 4/4 yang berarti bahwa dalam satu birama terdapat empat ketukan. Bentuk Marendeng Marampa'" terdiri atas dua bagian, yaitu A, B yang masing-masing memiliki motif dan semi frase, dan di dalam lagunya terdapat frase anteseden dan frase konsekuen.

Marendeng Marampa"' merupakan lagu pemersatu anak daerah terutama bagi mereka yang merantau di daerah lain agar selalu mengingat dan mengenang kampung halamannya, yakni Toraja. Lagu ini mempunyai makna bahwa susah atau senang yang dialami di rantau orang, harus tetap semangat dalam menjalani hidup: apa pun rintangannya, tetap berjuang...

\section{DAFTAR PUSTAKA}

Ariesta, I Jacky Made. 2017. "Analisis Bentuk dan Struktur Lagu Komposisi 'Morning Happiness' Karya Agus Teja Sentosa”, skripsi Program Studi Musik, Fakultas Seni Pertunjukan, Institut Seni Indonesia Denpasar.

Ariesta, I Made Jacky; Ardini, Ni Wayan; Darmayuda, I Komang; Sumerjana, Ketut. 2018. "Analisis Bentuk dan Struktur Komposisi 'Morning Happiness' Gus Teja", Journal of Music Science, Technology, and Industry, Vol. 1, No. 1, Oktober, http://jurnal.isi-dps.ac.id/index.php/jomsti/article/view/504. Date accessed: 10 Mei 2019.

Banoe, Pono. 2003. Kamus Musik. Yogyakarta: Kanisius.

Jamalus, Srs. 1998. Penggunaan Musik melalui Pengalaman Musik. Jakarta: Balai Penelitian dan Pengembangan Pendidikan dan Kebudayaan.

Mahardika, Komang Wira Adhi. 2018. "Lantunan Masa Kecil dalam 'Lullabybianu'”, Journal of Music Science, Technology, and Industry, Vol. 1, No. 1, Oktober, http://jurnal.isi-dps.ac.id/index.php/jomsti/article/view/505. Date accessed: 15 Juni 2019.

Matanari, Oang Gabriel; Darmayuda, I Komang; Ardini, Ni Wayan. 2019. "Belenggu Benalu": Komposisi Kolaborasi-Interpretatif mengenai Pengaruh Akulturasi Budaya Barat pada Musik Batak Toba "Uning-uningan", Journal of Music Science, Technology, and Industry, Vol. 2, No. 1, April, http://jurnal.isidps.ac.id/index.php/jomsti/article/view/612. Date accessed: 20 Mei 2019.

Moleong, Lexy J. 2001. Metode Penelitian Kualitatif. Bandung: PT. Remaja Rosdakarya.

Prier, SJ, Karl-Edmund. 2006. IImu Bentuk Musik. Yogyakarta: Pusat Musik Liturgi. 
Journal of Music Science, Technology, and Industry Vol. 2 No. 2 (2019): 169-184 E-ISSN 2622-8211

Putra, I Putu Adi Septa Suweca. 2019. "Analisis Komposisi Musik "Kuasa Tanah"”, Journal of Music Science, Technology, and Industry, Vol. 2, No. 1, April, http://jurnal.isi-dps.ac.id/index.php/jomsti/article/view/604. Date accessed: 14 Mei 2019.

Syafiq, Muhammad. 2003. Ensiklopedia Musik Klasik. Yogyakarta: Adi Cita. 